escapulares, mucosas pálidas, sopro sistólico com grau V/VI em foco tricúspide e pulmonar, pulso jugular positivo e catarata bilateral. O hemograma revelou anemia (hemácias = $3.530 .000 / \mathrm{ml}, \mathrm{VG}=24 \%$ ). A radiografia torácica indicou a presença de aumento cardíaco esquerdo e direito e abaulamento em região de artéria pulmonar. O eletrocardiograma revelou ritmo sinusal e padrão de aumento de ventrículo direito. Inicialmente o animal foi tratado com associação de pirantel/febantel/praziquantel, enrofloxacina e sucralfato. No dia 19/02/03 o paciente retornou com presença de ascite, insuficiência cardíaca direita e sinais de baixo débito cardíaco. O ecocardiograma indicou dilatação e hipertrofia de ventrículo direito, dilatação de átrio esquerdo, displasia de válvula tricúspide e estenose de válvula pulmonar. No mesmo dia foi realizado eletrocardiograma ambulatorial (Holter) que revelou a presença de inversão do complexo QRS sugestivo da Síndrome de Wolff-ParkinsonWhite. Foi prescrito maleato de enalapril, furosemida e amiodarona. A sincope é um sinal clínico comum na Síndrome de Wolff-Parkinson-White e está associada aos períodos de taquicardia supraventricular paroxística. Alguns animais podem não apresentar alteraçōes eletrocardiográficas sugestivas da sindrome no momento do exame por isso é fundamental a realização do eletrocardiograma ambulatorial (Holter) para confirmar o diagnóstico. A amiodarona é indicada para o tratamento porque aumenta o período refratário da via anômala, evitando, deste modo, os períodos de taquicardia supraventricular e os episódios de sincope.

\title{
4 - Tetralogia de Fallot em cão. Relato de caso
}

1- Residente em Clínica Médica de Pequenos Animais a Faculdade de Medicina Veterinária da Universidade Estadual Paulista, Campos de Botucatu, Botucatu-SP

2-Professora Assistente Doutora do Departamento de Clínica Veterinária a Faculdade de Medicina Veterinária da Universidade Estadual Paulista, Campos de Botucatu, Botucatu-SP

A tetralogia de Fallot é um defeito cardíaco congênito incomum em cães e gatos, caracterizado pela presença de defeito de septo ventricular, dextroposição da aorta, estenose pulmonar e hipertrofia ventricular direita. Quando a obstrução do fluxo de saída ventricular direito for grave, ocorrerá um desvio de sangue não oxigenado para a circulação sistêmica através do defeito de septo ventricular. Dessa forma, ocorre cianose generalizada e policitemia conseqüentes da hipoxemia. Este trabalho tem como objetivo descrever um caso de tetralogia de Fallot atendido no Hospital Veterinário da FMVZ (Unesp-Botucatu). O cão macho, da raça Poodle miniatura, com 2 meses de idade, apresentava histórico de intolerância ao exercício há 1 mês e quadro de dispnéia aguda e cianose há 1 dia. Ao exame físico verificouse a presença de sopro sistólico em foco pulmonar de grau V/VI e mucosas cianóticas. A radiografia de tórax demonstrou aumento de ventrículo direito. O ECG revelou aumento na amplitude da onda S na derivação CV6LL (V2) e desvio do eixo frontal para a direita, sugerindo um aumento de ventrículo direito. Ao hemograma observou-se policitemia, contudo sem alterações no leucograma e contagem de plaquetas. A hemogasometria evidenciou deficiência na oxigenaçào venosa. $\mathrm{O}$ exame ecocardiográfico demonstrou hipertrofia do ventrículo direito e defeito no septo ventricular. Foi realizado tratamento médico emergencial com fluidoterapia, oxigenoterapia e vasoconstrictor arterial (etilfecrina). Após 1 dia de tratamento o animal apresentava-se com melhora no quadro dispnéico e na cianose, contudo, começou a apresentar convulsões, provavelmente como conseqüencia de hipóxia cerebral Foi realizado o controle das convulsões com fármaco anti-convulsivante (fenobarbital) em bôlus seguida de infusão contínua. Sem apresentar melhora do quadro convulsivo, o animal entrou em status epileticos e veio à óbito neste mesmo dia. No exame necroscópico confirmou-se o diagnóstico de tetralogia de Fallot pela presença de hipertrofia ventricular direita acentuada, estenose pulmonar com presença de dilatação pós-estenótica, dextroposição da aorta e defeito de septo ventricular. Apesar da descrição de técnicas cirúrgicas paliativas para a correção da anormalidade, não foi possivel a realização das mesmas devido ao estado 
Silva, M.B.F.'; Carnicelli, C'; Rezende, A. C: ${ }^{2}$ Burgese, L.F?; Jericó, M. M. ${ }^{+}$ grave do paciente que evoluiu para o óbito. O diagnóstico precoce de problemas cardíacos congênitos é importante para a instituição do tratamento adequado na tentativa de melhorar a qualidade de vida e o prognóstico do animal. Dessa forma, é fundamental que se reconheça as características encontradas no histórico, exame físico e exames complementares de cada enfermidade para saber diferenciá-las adequadamente.

\section{5 - Avaliação eletrocardiográfica e da pressão arterial em cães obesos}

1- Grupo de Estudos em Obesidade Animal (ObeZoo) de Iniciação Cientifica do Departamento de Medicina Veterinária da Universidade Santo Amaro (UNISA), São Paulo-SP

2- Estagiária do Hospital Veterináriodo Departamento de Medicina Veterinária da Universidade Santo Amaro (UNISA), São Paulo-SP

3- Médico residente do Setor de Diagnóstico por Imagem Do Departamento de Medicina Veterinária da Universidade Santo Amaro (UNISA), São Paulo-SP

4-Coordenadora do Grupo de Estudos em Obesidade Animal (ObeZoo) de Iniciação Científica do Departamento de Medicina Veterinária da Universidade Santo Amaro (UNISA), São Paulo-SP

A obesidade, doença nutricional mais freqüente em cães, é uma condição orgânica, onde ocorre o armazenamento excessivo de energia sob a forma de tecido adiposo. A presença da obesidade predispòe o aparecimento de quadros mórbidos vários, dentre eles os problemas cardiovasculares. Objetivou-se a verificação da condiçào cardiovascular cm 31 càes obesos, com porcentagem de gordura corpóreos maior que $20 \%$, atendidos no Hospital Veterinário da UNISA, no periodo de fevereiro a julho de 2002, sendo 23 $(74 \%)$ fêmeas e sete $(23 \%)$ machos, dos quais seis $(19 \%)$ eram sem raça definida, quatro $(13 \%)$ cocker spaniel, quatro $(13 \%)$ poodles, quatro $(13 \%)$ schnauzers, dois $(6 \%)$ labradores, dois $(6 \%)$ pastores alemães, e outros nove $(29 \%)$ animais de raças diversas, de faixa etária entre 3 a 11 anos. A avaliaçào cardiovascular foi resultada por meio de traçado eletrocardiográfico e determinação da pressão arterial. Os resultados obtidos revelaram que na avaliação eletrocardiográfica, as observaçòes mais relevantes dizem respeito a 8 animais $(26 \%)$ apresentando segmento ST em abobada e cinco animais $(16 \%)$ com presença de R', cinco animais $(16 \%)$ com alteração de eixo com desvio para direita $\left(0 \mathrm{a}+30^{\circ}\right)$, outros dois animais $(6 \%)$ com alteração na amplitude da onda $\mathrm{P}$ de $0.6 \mathrm{mv}$; um animal $(3 \%)$ com alteração de duração de complexo QRS até $0.08 \mathrm{~s}$ e um animal $(3 \%)$ com alteração em ritmo cardíaco, sendo um bloqueio átrio ventricular de $1^{\circ}$ grau, tipo I. No que tange à avaliação da pressão arterial, doze animais $(44 \%)$ exibiram pressão arterial sistólica acima de $180 \mathrm{mmHg}$; sete animais (26\%) com pressão arterial diastólica acima de $140 \mathrm{mmHg}$. Concluiu-se que, na populaçào de càes obesos ora estudada, os achados eletrocardiográficos e de medidas de pressão arterial sugerem que uma porçào considerável dos animais apresenta evidências de hipertensào arterial periférica e de hipóxia, ou sofrimento, de miocárdio. 